\title{
University Basic Research
}

\author{
by Lee $A$. DuBridge
}

Granted that the fundamental arguments for pure research can be set forth

in impressive array - how much monetary investment is justified

each year, and how can it best be distributed?

The nation's program of basic research in science is at a critical juncture. Its future progress is by no means assured, and much will depend on the outcome of the debates now in progress. These debates are going on not only in scientific circles but also in the public press, in the halls of Congress, and in the offices and conference rooms of many government agencies. Pressures for reducing or leveling off research budgets are evident.

In this debate the advice and the views of many scientists will no doubt be heard. But the critical decisions will not be made by scientists, for important matters of public policy are involved.

Yet the scientific community must be involved in this debate. Scientists must look again at the goals, the potentialities, and the values of science and set them forth clearly and persuasively. These views must, in fact, be formulated so convincingly that non-scientists in high places will be able and willing to speak out for scientific advance as a vital national effort. It is often asserted that scientists are so prejudiced by their personal interests that they are no longer always to be believed. Nevertheless, the case for basic research in modern societyif there is one-must emerge from careful considerations set forth by scientists themselves, for no one else is likely to undertake the task.

It has, indeed, been well begun. It was begun over 20 years ago when the case for the federal support of science was first cogently set forth in the

"University Basic Research" first appeared in Science, Vol. 157, pp. 648650, 11 August 1967. Copyright 1967 by the American Association for the Advancement of Science. famous Bush report, Science-the Endless Frontier. The discussion has continued across the country, in Congress, and in the White House ever since. The recent definitive reports from the Committee on Science and Public Policy of the National Academy of Sciences have added much to the public record.

But obviously the task is not completed. Possibly it is scarcely begun. Here it may be well to start by trying to clear up a few misunderstandings.

First we must ask whether the case for or against basic research has changed in recent years or whether it merely needs to be stated in different terms. In fact, the basic case is unchanged. The arguments can be grouped under four headings.

1) Research-that is, inquiry into the nature of the physical and biological world-is a prime human urge. The advance of knowledge has in itself been an elevating, inspiring aspect of human history.

2) Basic research has uncovered knowledge which has made possible practical applications which have enormously affected human civilization.

3) This planet, on which 3 billion (soon to be 6 billion) human beings live, cannot become more habitable and a better place to be unless new knowledge is found to make possible new technologies and new ways of living. (The words food and population control illustrate what I mean.)

4) Scholarly inquiry is an indispensable role of institutions of higher education and has a unique function in educating the minds of the future.

Basic scientific research thus has cultural or human values which result from enlightenment of the mind, and it also makes possible the advance of 
technology. It has become a necessity for the future.

The case for these values of science can be, and has been, documented time and time again. If people are tired of hearing of the great results of the researches of Galileo, Newton, Faraday, Maxwell, Einstein, and the rest, there are many other examples that can be set forth. I suggest that we set them forth, repeatedly and convincingly. This is the case that must be documented. Man is better off today than he was 300 years ago, and science has done much to this end by combating superstition and prejudice, by allaying hunger and disease, by laying the base for technological advance. If the world's troubles still seem tragic and complex, this is so not because we have too much knowledge but because we have not learned how to use all our knowledge effectively.

And here the scientist must face and answer a new set of questions. If our great investment in pure and applied science has failed to cure all the world's ills-if, indeed, they are getting worse-should we not, in investing our money, focus more precisely on the problems of war, of overpopulation, of urban living, or of achieving a stable economy and a better way of life for all people?

The answer of course is yes, by all means! Science never pretended to be a solution for all human problems. Science is a search for truth about the physical world. The truth so far attained has led to solutions of some problems. These solutions have come as welcome by-products of scientific knowledge-so welcome that we now spend eight times as much money on exploiting the applications of scientific knowledge as on seeking new knowledge.

This is fine. Applied science is important too. It is also inherently more expensive than pure science and more profitable in terms of immediate results.

But the world's problems go far beyond the problems of science and technology. They include problems of human understanding; of fulfilling human hopes and human desires; of understanding the social, economic, and political institutions which men have created: of using the knowledge we have more intelligently.

Every sensible scientist will see the need for urgently seeking to understand and solve these problems, too. The university is the seat of the scholarly inquiry and the source of the trained minds needed for understanding and solving them. The universities need more resources for developing these humanistic and social studies.

We as scientists may not have very effective ideas on ways to proceed to solve these social problems, yet we cannot withdraw from the field. We are human beings. We will suffer or prosper as other hu- man beings do. Furthermore, many and possibly most of these problems have scientific and technological aspects. We can associate with our friends in the social and behavioral sciences and seek to help in areas where our help can be useful.

But society will not be well served if pure science is abandoned in this process or even substantially impeded in its growth. The values of science remain. All efforts and investments which the nation makes in tackling these other problems will pay off in their own right-just as our past efforts in science have paid off handsomely, even in purely economic terms.

Granted that the fundamental arguments for pure research can be set forth in impressive array, the question remains: How does one set forth to government representatives and the public just how much monetary investment is justified each year, and how it can best be distributed among subject matter fields, among projects, or among the 50 states.

Here the complexities of the problem begin to appear. And herein lie the challenges for initiating a fruitful discourse between the worlds of science and education and their various subworlds, the world of government officials and the world of influential taxpayers. No one of these worlds, of course, is a unified one; each contains individuals and groups with widely differing attitudes, beliefs, experiences, responsibilities, and concerns. We cannot expect to find unanimity within any of these worlds, much less full agreement between them. Yet, by some form of consensus and compromise, an agreement-or a decision-on national policy must be consummated.

A few points should be stressed.

1) The present annual investment in basic scientific research in universities (about $\$ 1$ billion) is sometimes said to be "extravagant." But if we observe the results and observe the nation's scientific potential, we must conclude that this sum is a sound investment in the future. It is indeed an inadequate investment in terms of the opportunities which lie ahead and of the needs of the government agencies which support it. Every field of science sees opportunities unrealized.

2) We have purposely, during the past 20 years, expanded the scientific community by training many young scientists at great expense. Do we not intend to put their talents to good use? Clearly, support of science must not stay at current levels; it must increase in order that we may capitalize on the trained talents of these young investigators, meet rapidly rising research costs, and exploit currently neglected fields.

3) We must clarify the role of basic science as compared to applied science, to engineering, and 


\section{The case for basic research in modern society - if there is one-}

\section{must be set forth by scientists themselves.}

to putting to beneficial use our new scientific knowledge. These are overlapping areas of endeavor with fuzzy boundaries. Yet each has its special and distinct place in our national effort; each depends upon the others. It is folly to neglect any one.

4) Most of the current federal expenditures for university-based research and education in science do not come from a direct effort to support such enterprises but accrue indirectly from government expenditures aimed at other national goals.

On this last point, for example, it is a matter of national policy-and of national necessity-that we improve our military technology. The Department of Defense spends large sums for this purpose. In the process it has found it necessary and desirable to encourage a comparatively modest amount of basic research in areas of science which seem to have immediate or long-range relevance to defense technology. When the Department of Defense finds, in a university, competent scientists who wish to undertake such research, is it not prudent to use their talents? Is it proper to regard such contracts as "handouts" or "benefactions" to the universities? Are the universities not simply performing a necessary public service?

The nation also has an established policy of advancing the technology of atomic energy for both military and peaceful purposes, of conducting a large program of space exploration, of seeking to improve the public health and to advance the conquest of disease. These and other missions in the national interest are assigned to appropriate government agencies for implementation. Each such agency turns, to a greater or lesser degree, to universities for relevant basic investigations. The scientists and the universities concerned welcome these research tasks whenever they fall within their realms of interest, enthusiams, or competence. A scientist and his institution are fortunate when it is found that the kind of research they wish to do also serves a national purpose, in that some mission-oriented government agency deems it relevant to its mission. These agencies are not authorized to give handouts to universities; they are not philanthropic institutions. They are properly charged with investing taxpayers' money in those research activities which promise to yield the greatest return. They have set up mechanisms for selecting with great care and great expertise just which of the many proposed projects they will finance. These tasks of se- lection have been performed with conspicuous success and integrity. It is not the fault of the agencies concerned if scientific competence has been found to be more plentiful in some parts of the country than in others.

Some 85 percent of the basic research funds allocated to universities has been placed by missionoriented agencies in support of their own missions. In a sense it is only accidental if university science has been thereby strengthened.

Only 15 percent of the dollars for university research comes from the one agency which is authorized to support general basic research not visibly relevant to specific government requirements or goals. The National Science Foundation grants for research total only about $\$ 175$ million a year. These grants go to hundreds of colleges and universities, large and small, throughout the nation, supporting important fields of science. The NSF has the most extensive array of expert committees and consultants of any agency, plus a large professional staff, to insure fruitful expenditure of funds. It seeks to be the balance wheel for the national science program. It has never had enough funds for this.

Now what is wrong with this whole picture? Basically, nothing! Yes, there have been administrative headaches on all sides. No system operates perfectly. Some abuses have crept in here and there. Not all experts agree on the areas of importance or on the relative merit and promise of various project proposals. It is not easy for a mission-oriented agency to judge which research areas are really "relevant" to its mission. Every scientific discipline contains many members (often a large majority) who feel that their subject is inadequately supported. And they can usually prove it by pointing to opportunities unrealized, to promising young scientists inadequately supported.

But is a major overhaul of the system either necessary or desirable? I know of no widely accepted proposals for such an overhaul. Most of the arguments and misunderstandings about the total effectiveness of the system are based on conflicting opinions as to the relative importance of the various objectives of the mission-oriented agencies. It is said by some that we are spending too much on space and not enough on cancer-or vice versa; too much on military development and not enough on weather modification or oceanography or atomic energy.

Now these national policy objectives are deter- 
mined by the legislative and executive branches of the government on the basis of considerations having little to do with the progress of basic science. Military strength, the practical exploitation of atomic energy, the conquest of disease, the proper use of national resources are all judged by the government to have inherent value or to be necessary in their own right, and it is only proper that all relevant resources for implementing these objectives, including the resources of university science, be employed. That many university science and engineering activities in teaching and research have benefited from the services they have rendered to the mission-oriented agencies is undeniable-and very fortunate! It is also fortunate that a fairly broad-based program of research support has emerged, thanks to extensive cooperation among the agencies involved. Understandably, however, there are serious gaps.

The confusion about the relation of basic science to national-policy objectives is probably most evident in the space program. Is the purpose of that program to extend scientific knowledge or to enhance national prestige or to achieve other objectives? Obviously the space program has many aims and objectives, and there is wide disagreement as to which ones take priority. Those who feel (wrongly) that the principal aim of Congress in supporting NASA is the advance of basic science contend (rightly) that $\$ 5$ billion a year could be more fruitfully expended in other ways. Those who believe that the principal objectives of the space program are to enhance national prestige or to satisfy a human urge for exploration, or to assure future military or economic dividends, argue that some or all of these objectives are being achieved and that the total result is worth $\$ 5$ billion a year. Clearly the question is not a scientific one; it is one of public policy. And those in the Congress and the executive branch responsible for establishing public policy have decided that the expenditure is justified. Those who disagree are entitled to say so-and they do.

Scientists who insist that this $\$ 5$ billion could be more profitably expended for other scientific enterprises may be right, but they miss the point. The $\$ 5$ billion is not being spent primarily to advance science any more than the $\$ 50$ billion expended by the Defense Department is. Yet in both cases a moderate fraction of the budget is necessarily used to advance science. In the space program the resulting technologies are providing a valuable tool for carrying on scientific investigations which would otherwise be impossible. Many scientists are welcoming the opportunity to ride piggyback on this great venture and thereby to greatly advance ter- restrial, space, and planetary science.

However, it must again be stressed that neither NASA nor any other agency charged with implementing national policy is intended to be a philanthropic agency authorized to provide benefactions to university science departments. They are agencies seeking to get a job done, and they turn to universities only when the universities can render a service-a service usually rendered at less than cost.

If the government wishes, as I believe it should, to develop a more adequate and more balanced program for strengthening American science per se, then it should charge suitable agencies, principally the National Science Foundation, with this particular task and provide funds for carrying it out.

As I have said, there is nothing basically wrong with the system. But there are serious dangers ahead in its current operations. The degree to which mission-oriented agencies of government will invest their precious funds in the rather long-range benefits to be expected from basic science will vary. Already there are pressures for concentrating on more immediate results. Project Hindsight will be used by some as an argument to this end, showing, as it does, that the results of undirected research appear in the form of new weapons only many years later. Mission-oriented agencies are, understandably, in a hurry. Can we afford to let the basic knowledge so necessary for future progress depend on the winds of political and economic pressures which blow hot or cold today?

A ready solution is at hand. The National Science Foundation can be depended on to look to the longrange future. It can be depended upon to recognize the cultural as well as the practical values of basic science. It can serve as the balance wheel to promote the broad advance of science-if its research budget is substantially increased.

The budget levels for NSF are determined by the Bureau of the Budget and by the House and Senate appropriation committees, agencies to which scientists at large and the general public have almost no access. The burden of presenting the needs of science thus falls almost solely on the members of the Board and the staff of NSF, aided only by the behind-the-scenes work of the President's Advisory Committee.

Here is a serious flaw in an otherwise viable system. Herein lies the need for a widespread public discussion of the issues-so that all congressmen and senators become aware of the real values and needs of basic science and of the critical role which can and should be played by NSF. Presumably, only wide public support will have the required influence on the appropriate committees and offices. 